\title{
Responses of water environmental indicators to climate conditions in the middle and lower reaches of Lijiang River
}

Dantong Zhu ( $\nabla$ ctzhudantong@mail.scut.edu.cn )

South China University of Technology https://orcid.org/0000-0001-5022-8108

Xiangju Cheng

South China University of Technology

Wuhua Li

South China University of Technology

Fujun Niu

South China University of Technology

Jianhui Wen

Guilin Environmental Monitoring Center

\section{Research Article}

Keywords: climate condition, water quality, sensitivity coefficient, contribution rate, Lijiang River, dominant factor

Posted Date: November 15th, 2021

DOI: https://doi.org/10.21203/rs.3.rs-1074127/v1

License: (1) This work is licensed under a Creative Commons Attribution 4.0 International License.

Read Full License 


\section{2 conditions in the middle and lower reaches of Lijiang River \\ Responses of water environmental indicators to climate}

\author{
Dantong Zhu ${ }^{1,2,3}$ Xiangju Cheng ${ }^{1,2,3, *}$ Wuhua Li $^{2}$ Fujun Niu ${ }^{1,2,3}$ Jianhui Wen $^{4}$
}

1 State Key Laboratory of Subtropical Building Science, South China University of Technology, Guangzhou 510640, China.

2 School of Civil Engineering and Transportation, South China University of Technology, Guangzhou 510640, China.

3 South China Institution of Geotechnical Engineering, School of Civil Engineering and Transportation, South China University of Technology, Guangzhou, 510640, China

4 Guilin Environmental Monitoring Center, Guilin, 541002, China

* Corresponding author. E-mail address: chengxiangju@scut.edu.cn (Xiangju Cheng)

Abstract: With global climate change and increasingly extreme weather conditions, the water environment of the Lijiang River Basin is facing huge threats. Past studies have mostly focused on large-scale areas or have regional characteristics. Therefore, this study is based on the meteorological, hydrological, and water quality data of the Lijiang River from 2012 to 2018, using the analysis method Spearman's rank correlation coefficient, sensitivity, and contribution rate to quantitative analysis of the relationship between climate conditions and water environment indicators. The results show that the oxidation and alkalinity of the water in the Lijiang River Basin gradually increase, and the intensity becomes stronger as it goes downstream. DO increase and the concentrations of $\mathrm{COD}_{\mathrm{Mn}}, \mathrm{BOD}_{5}$, and $\mathrm{NH}_{4}-\mathrm{N}$ all decreased, and water quality improved year by year. The input of external pollution has led to an upward trend in TP in Yangshuo. DO is positively correlated with wind speed and negatively correlated with other climate indicators. $\mathrm{NH}_{4}-\mathrm{N}$ and $\mathrm{TP}$ are mainly affected by precipitation, streamflow, humidity, and sunshine duration, only sunshine duration is negatively correlated. Pollutants from Guilin to Yangshuo on both sides of the Lijiang River were carried by the surface runoff into the water body contain a certain amount of organic matter and acidic matter. Water 
environment indicators are not very sensitive to precipitation and streamflow, humidity and wind speed have higher sensitivity. Water temperature and sunshine duration have a positive effect on reducing $\mathrm{NH}_{4}-\mathrm{N}$ and TP. Various climate conditions can help reduce organic matter in the water body where there are few external sources and the opposite contribution with external sources. No climate condition can dominate one water environment indicator of two stations at the same time. The difference between Yangshuo and Guilin is mostly due to the input of external sources on both sides of the Lijiang River, which leads to the difference in sensitive climate conditions. Construction of non-point source pollution reduction facilities and sewage treatment measures are very necessary.

Key words: climate condition; water quality; sensitivity coefficient; contribution rate; Lijiang River; dominant factor

\section{Introduction}

For many years, environmental water governance has been an important issue that has plagued the government and scientific researchers (Stackpoole et al. 2019; Yu et al. 2019). With the development of water treatment technology, improved human awareness of environmental protection, and the publication of government regulations, water quality has improved considerably, and point source pollution has also been well controlled (Wang et al. 2018b). Where non-point source pollution becomes the main problem in pollution control, the overall trend of global climate change has brought potentially enormous risks to the protection and governance of the water environment (Qiu et al. 2019; Li and Kim 2019; Bai et al. 2020). As we all know, non-point source pollution enters water bodies through atmospheric deposition and surface runoff. Therefore, it is necessary to explore the impact of climate change on the water environment.

The impact of climate conditions on the changes in the water environment has attracted the attention of many experts. Water resources have the most evident change that is affected by climate, and numerous studies have started to focus on this aspect, combined with local climatic and hydrologic conditions and policy documents to analyze and make relevant decisions and recommendations (Sowers et al. 2010; Grafton et al. 2012). Related topics such as precipitation, 
drought, and evaporation have become a hot topic in global research, including risk assessment (Ahmadalipour et al. 2019) and forecasting future changes (Dai et al. 2018), etc. In regard to the water quality response to climate change, various studies are carried out on rivers, lakes, and reservoirs using General Circulation Models to predict climate change and then simulate water quality (Hosseini et al. 2017; Sjerps et al. 2017; Wang et al. 2018a). Land use change, population growth, economic growth, and other data were also be used to collaboratively analyze the impact of climate change (Shrestha et al. 2018; Olaoye et al. 2021). However, because of the completeness of the data quantity and the problems associated with the application, existing research is mainly carried out in hydrology, and the research scale is large, mostly at large river basins, national, and global scales. There is also an absence of research on water quality. At the same time, because of the differences in conditions such as climate, topography, and water quality, research results from a single basin are not well applicable to other regions and cannot effectively assist in water quality improvement, prevention, and policy development.

The Lijiang River is the soul of Guilin Landscape, and one of the key protected rivers in China (Xiao et al. 2021). The Lijiang River Basin is a typical karst landform with less land available. However, in recent years, with economic development, population growth, and tourism development, land on both sides of the Lijiang River has been extensively exploited, land use patterns have also changed accordingly, and agricultural non-point source pollution has increased significantly. The Lijiang River is a rain-source river in the monsoon region ( $\mathrm{Li}$ et al. 2015). During the same period of rain and heat, precipitation and streamflow are closely related. Due to the gradual destruction of the water source forest community structure and the increase in industrial, agricultural, and urban water consumption, water resources of the Lijiang River are seriously unbalanced, environmental quality and ecological system balance have been damaged (Liu et al. 2017; Li et al. 2021), and water environment quality has significant temporal and spatial differences (Zhao et al. 2020; Wang et al. 2020). With the increase in extreme weather conditions, the Lijiang River Basin is also facing threats to the water environment caused by climate change.

In order to have a clearer understanding of the relationship between climate change and water environment changes in the Lijiang River Basin, the objectives of this paper were: (1) 
explain the temporal and spatial changes of climatic and water environmental indicators in the middle and lower reaches of the Lijiang River; (2) quantify the correlation and sensitivity between climate conditions and water environment indicators; (3) evaluate the contribution rate of climate conditions to water environmental indicators and make recommendations for the protection of the water environment. The results of the quantitative analysis of this study will provide a scientific basis for the Lijiang River Basin to cope with the changes in the water environment caused by climate change.

\section{Methodology}

\subsection{Study area}

The Lijiang River Basin originated in Guilin, Guangxi, P.R.C., and is part of the Pearl River system. It has a total length of about $214 \mathrm{~km}$ and a drainage area of approximately 5800 $\mathrm{km}^{2}$, as shown in Figure 1. The extreme minimum temperature, extreme maximum temperature, and the annual average temperature in the Lijiang River Basin are $-4.0^{\circ} \mathrm{C}, 39.0^{\circ} \mathrm{C}$, and $18.8^{\circ} \mathrm{C}$, respectively. The northerly wind prevails throughout the year. The Lijiang River is a rainsourced river, and its runoff is significantly affected by precipitation. The average precipitation in the basin over the years is $1900 \mathrm{~mm}$, and the average evaporation is $1485 \mathrm{~mm}$. The rainy season lasts from late February to mid-August, with a relative humidity of $92 \%$. 


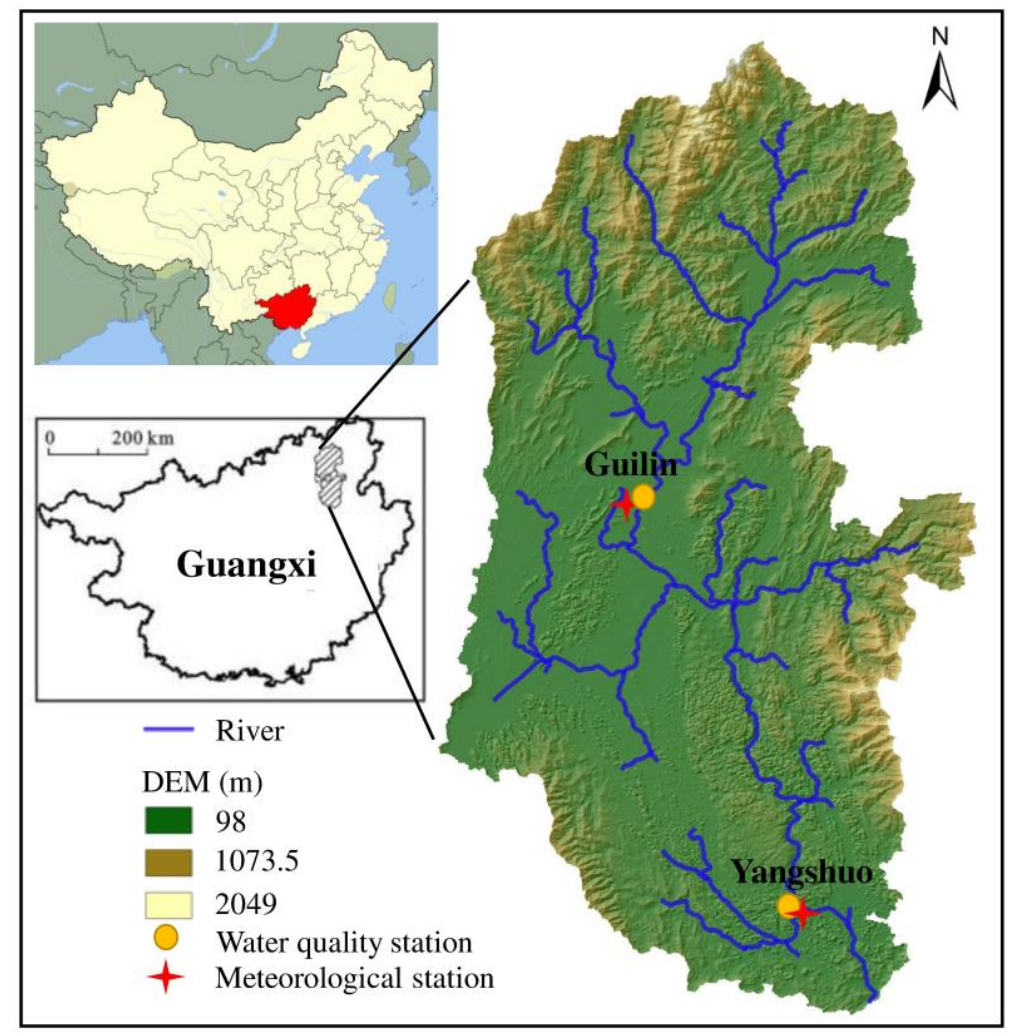

Figure 1 Study area and location of monitoring stations

\subsection{Data source}

The meteorological data comes from the National Meteorological Science Data Center (http://data.cma.cn/), and the hydrological data comes from the Guilin Hydrological Bureau. The monitoring stations are located in Guilin and Yangshuo (Figure 1), including daily maximum temperature, minimum temperature, precipitation, sunshine duration, wind speed, humidity, streamflow, and other indicators, the data scale is a daily scale. Water quality data were obtained by combining manual and automatic monitoring. The stations are shown in Table 1, including environmental factors such as water temperature, $\mathrm{pH}$, dissolved oxygen (DO), oxidation-reduction potential (ORP), etc., and water quality indicators such as ammonia nitrogen $\left(\mathrm{NH}_{4}-\mathrm{N}\right)$, total phosphorus (TP), etc., the data scale is monthly. Due to the different data scales, the meteorological and hydrological data are downscaled in this study, and the calculated monthly data are daily averages.

Table 1 Information of monitoring stations

\begin{tabular}{cccc}
\hline Type of data & Monitoring indicators & Stations & Location \\
\hline \multirow{2}{*}{ Meteorological } & $\begin{array}{c}\text { Air temperature, precipitation, } \\
\text { wind speed, etc. }\end{array}$ & Guilin & $110^{\circ} 18^{\prime} \mathrm{E}, 25^{\circ} 19^{\prime} \mathrm{N}$ \\
& Streamflow & Yangshuo & $110^{\circ} 30^{\prime} \mathrm{E}, 24^{\circ} 46^{\prime} \mathrm{N}$ \\
\hline Hydrological & & Guilin & $110^{\circ} 19^{\prime} \mathrm{E}, 25^{\circ} 14^{\prime} \mathrm{N}$
\end{tabular}




\begin{tabular}{|c|c|c|c|}
\hline & & Yangshuo & $110^{\circ} 30^{\prime} \mathrm{E}, \quad 24^{\circ} 46^{\prime} \mathrm{N}$ \\
\hline \multirow{2}{*}{ Water quality } & \multirow{2}{*}{$\mathrm{DO}, \mathrm{pH}, \mathrm{BOD}_{5}$, etc. } & Guilin & $110^{\circ} 19^{\prime} \mathrm{E}, \quad 25^{\circ} 19^{\prime} \mathrm{N}$ \\
\hline & & Yangshuo & $110^{\circ} 29^{\prime} \mathrm{E}, \quad 24^{\circ} 47^{\prime} \mathrm{N}$ \\
\hline
\end{tabular}

\subsection{Analysis method}

\subsubsection{Trend analysis}

In order to analyze the temporal and spatial evolution of climate indicators in the study area, we used the unary linear regression trend method to analyze the change trend and intensity on the time scale of the data of different monitoring stations in the Lijiang River Basin. The slope of the regression equation reflects the changing trend of the climate index. A slope above 0 indicates that the index is on the rise in the time range, and vice versa is a downward trend. The magnitude of the slope can reflect the magnitude of the increase or decrease of the index. The calculation formula is as follows:

$$
\theta=\frac{n \times \sum_{i=1}^{n}(i \times C)-\left(\sum_{i=1}^{n} i\right)\left(\sum_{i=1}^{n} C\right)}{n \times \sum_{i=1}^{n} i^{2}-\left(\sum_{i=1}^{n} i\right)^{2}}
$$

132 Where $\theta$ is the changing trend, $i$ is the time (month), $n$ is the study period, and $C$ is the climate 133 index at the time $i$.

\section{$134 \quad 2.3 .2$ Correlation analysis}

135 Climate conditions impact water quality indicators differently. In this study, correlation 136 analysis methods are used to quantify the correlation between the two indicators. Due to the poor regularity of the measured data and occasional outliers, the Spearman rank correlation coefficient method is adopted. This method does not require the distribution of the original variables and has a wider application range than the Pearson correlation coefficient (Schober and Schwarte 2018). While the Spearman correlation coefficient has an outlier value, the rank of the outlier usually does not change significantly, so the influence on the Spearman correlation coefficient is very low. For the original data with a sample size of $n$, the correlation coefficient $\rho$ is:

$$
\rho=\frac{\sum_{i}\left(x_{i}-\bar{x}\right)\left(y_{i}-\bar{y}\right)}{\sqrt{\sum_{i}\left(x_{i}-\bar{x}\right)^{2} \sum_{i}\left(y_{i}-\bar{y}\right)^{2}}}
$$

145 Where $x_{i}, y_{i}$ are the average of the descending position of each raw data.

\subsubsection{Sensitivity of water environmental indicators to climate conditions}


on the relative changes in the concentration of water quality indicators. This study uses the sensitivity coefficient defined by McCuen (1974) to analyze the sensitivity of different water quality indicators in the Lijiang River Basin to climate conditions, calculated as follows:

$$
S(C l)=\lim _{\Delta C l \rightarrow 0}\left(\frac{\Delta W Q / W Q}{\Delta C l / C l}\right)=\frac{\partial W Q}{\partial C l} \cdot \frac{C l}{W Q}
$$

Where $S(C l)$ is the sensitivity coefficient of water quality indicators to climate conditions. The higher the absolute value of the sensitivity coefficient, the larger the impact of relative changes in climate conditions on relative changes in water quality indicators. $W Q$ and $C l$ represent water quality indicators and climate conditions, respectively. The advantage of the sensitivity coefficient is that it is dimensionless and can be compared between a variety of different dimensions.

\subsubsection{Contribution rate}

The contribution rate of climate conditions is obtained by multiplying the sensitivity coefficient and the relative change rate of the indicator over the years, and the calculation formula is as follows:

$$
\left\{\begin{array}{l}
\operatorname{Con}_{C l}=S(C l) \cdot R C_{C l} \\
R C_{C l}=\frac{n \times a_{C l}}{|\overline{C l}|} \times 100 \%
\end{array}\right.
$$

Where $\mathrm{Con}_{\mathrm{Cl}}$ is the contribution rate of climate condition $\mathrm{Cl}$ to the change of water environment index $W E, R C_{C l}$ is the multi-year relative change rate of climate conditions, $n$ is the number of months, $a_{C l}$ is the changing trend of climate condition, $\overline{C l}$ is the monthly average of climate conditions.

\section{Results and discussion}

\subsection{Climate conditions}

Under the influence of global climate change, the climate conditions in the Lijiang River Basin have also undergone some changes over the past few years. Although the distance is not far, there are differences in some climatic data between Guilin and Yangshuo (Figure 2). Air temperature, water temperature, and sunshine duration gradually increase over time. On the one hand, different regions have different degrees of temperature increase caused by global warming; on the other hand, the increase in sunshine duration leads to higher absorption of heat, which increases the air temperature and water temperature. The difference between the 2 
monitoring stations of the 3 indicators is unclear, the temperature is a little bit higher in

177 Yangshuo than in Guilin due to the lower latitude. The air temperature in Guilin exceeded

178 Yangshuo in the period 2016 2018 whereas the water temperature did not appear the same

179 phenomenon, indicating that the heat island effect caused by urbanization primarily affects air

180 temperature.
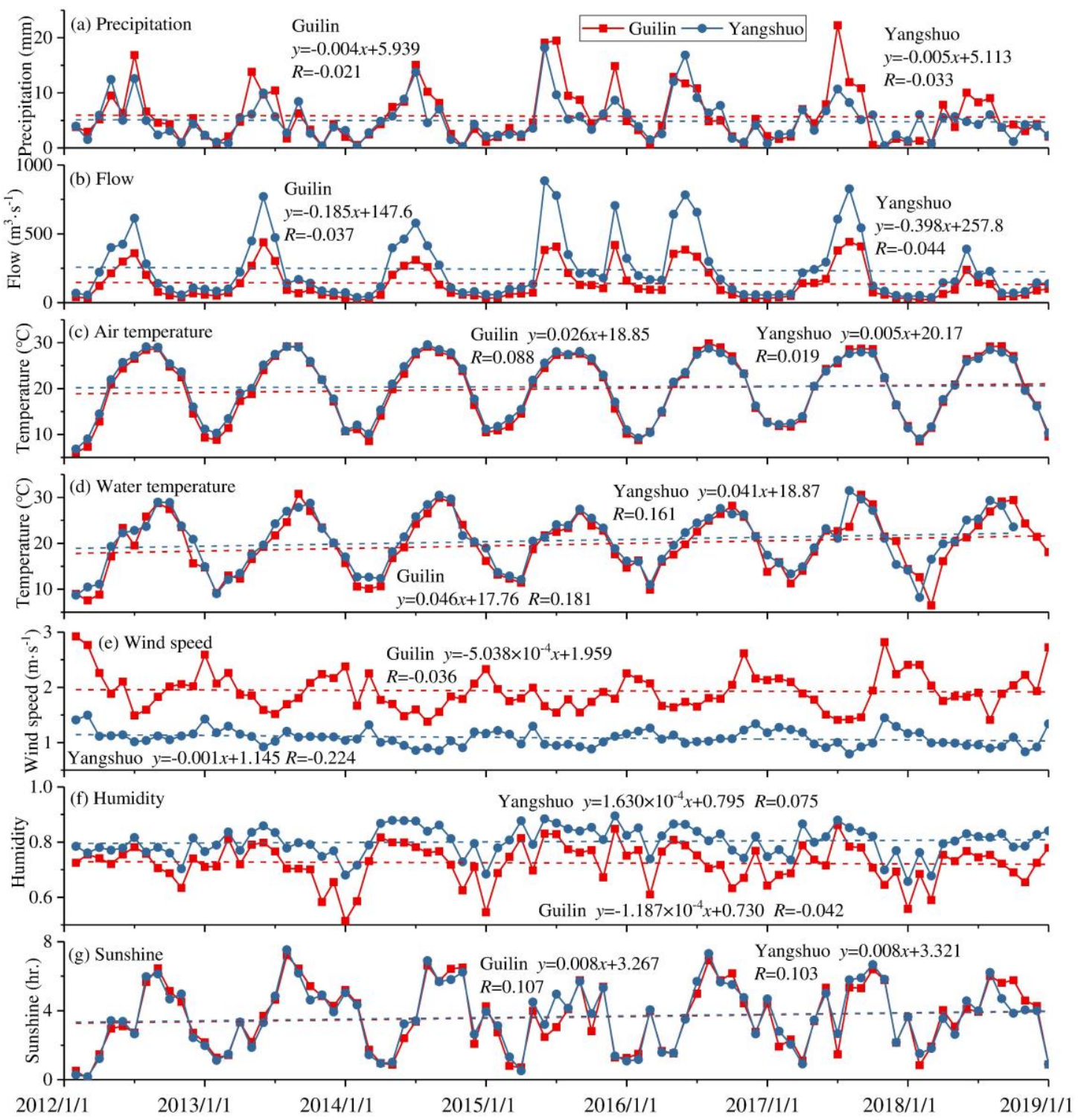

Figure 2 The evolution trend of climate conditions

Precipitation and streamflow have decreased with time. As a rain source basin, streamflow and precipitation are highly consistent, the difference between Guilin and Yangshuo is primarily reflected in the amount of increased streamflow caused by each rain. There is not a significant difference in precipitation between Guilin and Yangshuo, thus we analyze the correlation between precipitation and streamflow (Figure 3), correlation coefficients $(R)$ between 
precipitation and streamflow are 0.871 and 0.829 at Guilin and Yangshuo, respectively, show high correlation. However, $R$ between Guilin precipitation and Yangshuo streamflow is 0.881 , higher than that of the same stations, which means the precipitation has a higher influence on the downstream than the local area. Yangshuo also received discharges and runoff from other tributaries and their basins, make it a higher flow than Guilin.

193

194
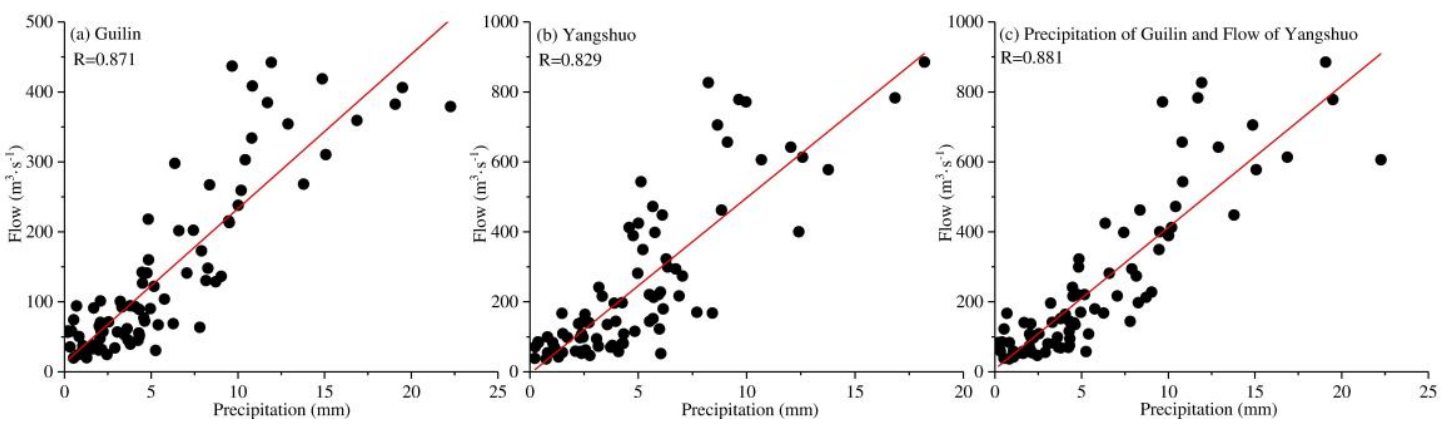

Figure 3 Correlation between precipitation and streamflow

Wind speed and humidity are the only two climate indicators that reflect large spatial differences. The wind speed of both stations and Guilin's humidity decreased with time while Yangshuo's humidity increased. Although the trends are different, the slopes are very low, almost all below 0.001 . These 2 climate indicators are the most stable in global warming conditions. Wind speed and humidity in both stations are opposite, the average wind speed in Guilin is 1.78 times that of Yangshuo and the average humidity is only 0.9 times that of Yangshuo. Guilin station is located in Guilin City while Yangshuo station is located in a county town, urbanization can lead to a significant wind reduction in urban areas (Peng et al. 2018), and the city is relatively drier than a rural area. These climatic differences caused by urbanization will also have some effect on water quality.

\subsection{Water quality indicators}

Water environment indicators have undergone inter-annual changes in response to external factors, as shown in Figure 4. The $\mathrm{pH}$ and ORP in Yangshuo are significantly higher than in Guilin and both have been increasing in recent years ( $\mathrm{pH}$ decreases first, then increases), indicating that the oxidative and alkaline properties of the water in the Lijiang River Basin are gradually increasing and that the intensity is getting stronger downstream. The overall DO is on the rise, while the concentration of $\mathrm{COD}_{\mathrm{Mn}}, \mathrm{BOD}_{5}$, and $\mathrm{NH}_{4}-\mathrm{N}$ are all declining, which means that water quality is getting better year by year. However, TP was declined in Guilin and 
214 the two stations, external pollution input could be the main reason for the gap. In recent years, 215 the land on both sides of the Lijiang River has been extensively developed. The increase in 216 agricultural land has aggravated the emission of nutrients. Most of the phosphate fertilizer is diammonium phosphate, and the aqueous solution of diammonium phosphate is weakly alkaline (Luo et al. 2020), makes the $\mathrm{pH}$ value increased in Yangshuo.
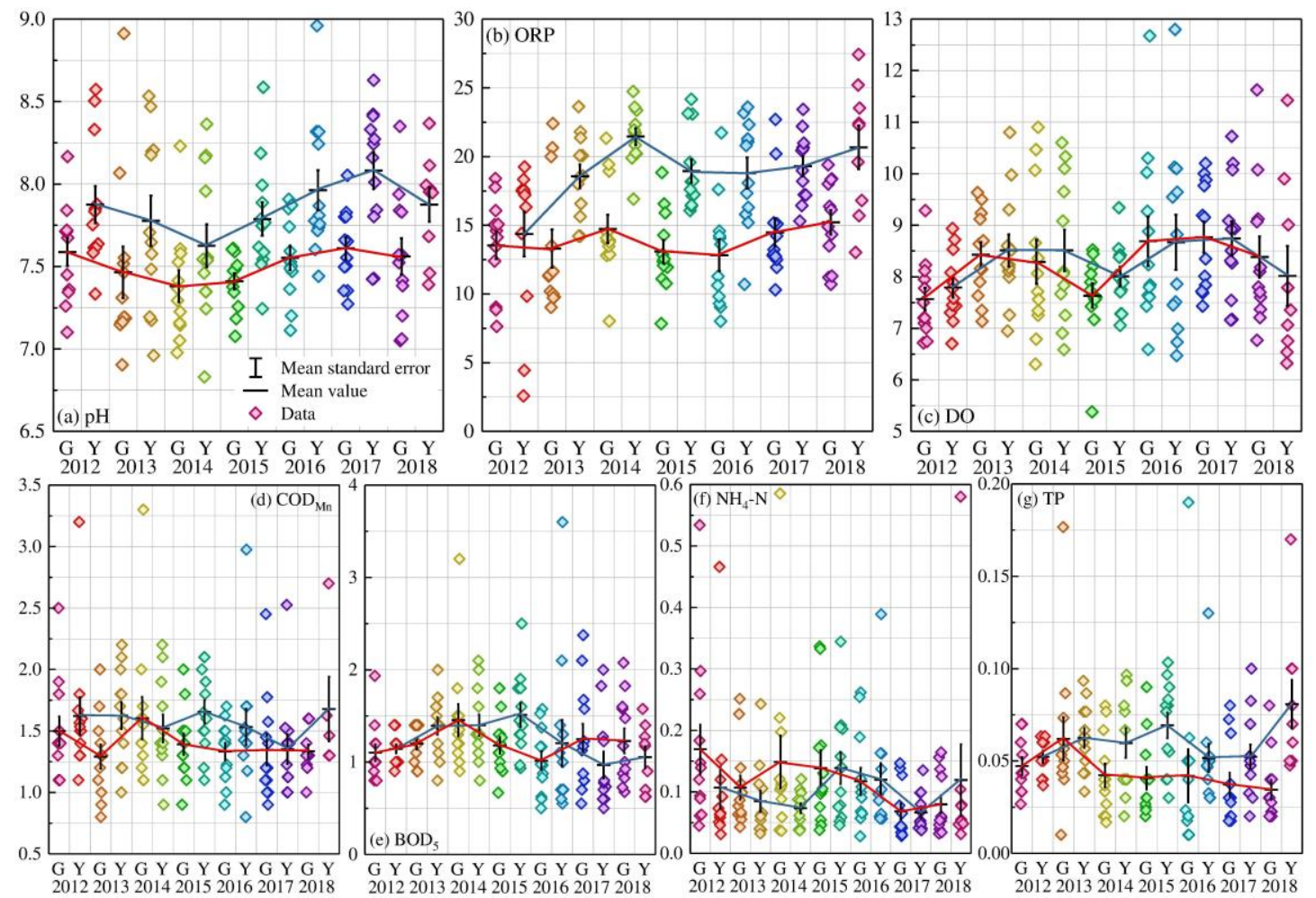

Note: "G" refers to Guilin, "Y" refers to Yangshuo.

Figure 4 Changes and differences in water quality at different monitoring stations

\subsection{Correlation analysis}

As a common influencing factor, climatic factors play an important role in the migration and transformation of water pollution, thereby affecting the concentration of water pollution and the quality of the water environment. Different climate conditions have different impacts on the water environment, and the impacts also have spatial differences. We use climatic factors precipitation, flow, air temperature, water temperature, wind speed, humidity, and sunshine duration as the abscissas, and water environmental indicators $\mathrm{pH}, \mathrm{ORP}, \mathrm{DO}, \mathrm{COD}_{\mathrm{Mn}}, \mathrm{BOD}_{5}$, $\mathrm{NH}_{4}-\mathrm{N}$, and TP as the ordinates, showing the distribution of water environment indicators for different climatic factors in different monitoring stations (Figure 5). 


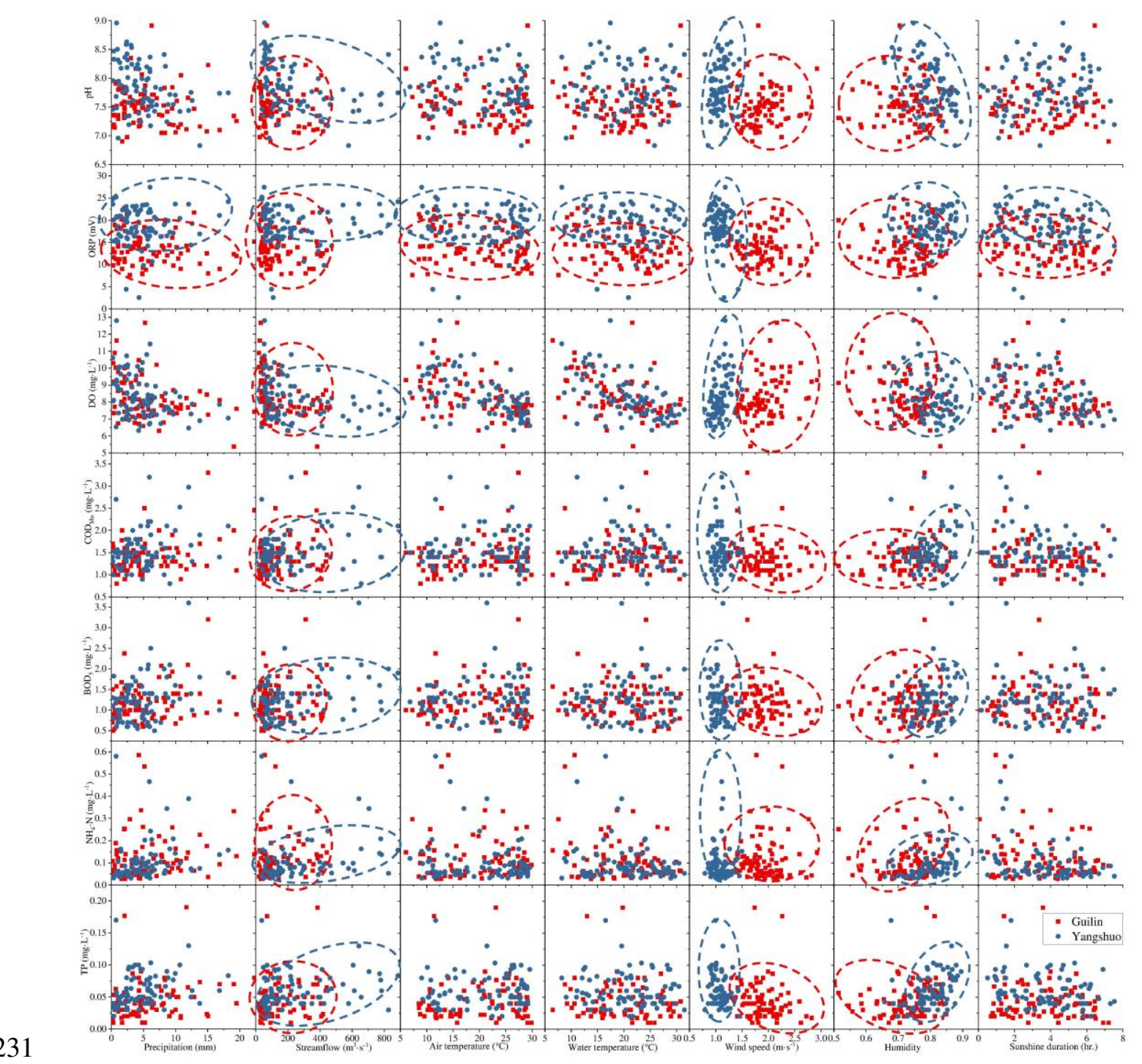

Figure 5 Differences in the impact of climate conditions at different stations on water

235 have obvious spatial differences that are mainly derived from the spatial differences of these

236 indicators themselves. The water environment indicators at Yangshuo do not seem to change

237 with the wind speed, but there is a trend of increasing or decreasing with the increase of wind

238 speed in various water environment indicators at Guilin. The difference in the distribution of

239 water environment indicators and humidity at different monitoring stations reflects the spatial

240 difference in the influence of humidity on it, with different concentration distributions and

241 changing trends. Although the $\mathrm{pH}$ and ORP of Yangshuo are considerably higher than that of

242 Guilin, only the ORP shows the spatial difference of concentration and change trend with the

243 change of climate indicators in the scattered point distribution. 

stations, and the Spearman correlation coefficients between climate conditions and water

246 environment indicators at different stations are shown in Table 2. Not all indicators are 247 statistically correlated. From the results, different water environment indicators at the same 248 stations have different correlations with climate indicators, and the same water environment 249 indicators at different stations have different correlated indicators as well. Except for the 250 precipitation in Guilin, $\mathrm{COD}_{\mathrm{Mn}}$ has no significant correlation with other climate indicators. As 251 one of the most important indicators in water bodies, DO has significant correlations with 252 almost all climate conditions. Apart from the positive correlation between wind speed and DO 253 concentration, other climate indicators are negatively correlated with DO, that is, the increase 254 of other indicators will increase the consumption of DO in the water body, resulting in a decline 255 in water quality. Among them, the correlation between temperature and DO has reached over 2560.56 , which is close to a strong correlation $(\rho>0.6)$. The increase of sunshine duration and 257 temperature will accelerate the biochemical reaction in the water body, resulting in an increase 258 in DO consumption. Increased precipitation and streamflow mean that surface contaminants 259 enter the water body with runoff, indicating that the environmental quality of the ground surface 260 is poor and that the water body is readily polluted. The wind speed accelerates the exchange of 261 oxygen between water and air and promotes the absorption of oxygen by water, thereby 262 increasing the DO concentration.

263 Table 2 Spearman's rank correlation coefficient of climate conditions and water environment 264 indicators

\begin{tabular}{ccccccccc}
\hline & & $\mathrm{pH}$ & $\mathrm{ORP}$ & $\mathrm{DO}$ & $\mathrm{COD}_{\mathrm{Mn}}$ & $\mathrm{BOD}_{5}$ & $\mathrm{NH}_{4}-\mathrm{N}$ & $\mathrm{TP}$ \\
\hline \multirow{6}{*}{ Guilin } & Precipitation & -0.076 & -0.179 & $-0.380^{* *}$ & $0.233^{*}$ & 0.184 & $0.286^{* *}$ & $0.319^{* *}$ \\
& Streamflow & -0.137 & $-0.258^{*}$ & $-0.398^{* *}$ & 0.157 & 0.103 & $0.302^{* *}$ & $0.260^{*}$ \\
& Air Temp. & -0.065 & $-0.317^{* *}$ & $-0.581^{* *}$ & 0.144 & -0.022 & 0.001 & 0.027 \\
& Water Temp. & 0.008 & $-0.308^{* *}$ & $-0.561^{* *}$ & 0.140 & -0.114 & -0.130 & -0.097 \\
& Wind Speed & $0.233^{*}$ & 0.050 & $0.373^{* *}$ & -0.144 & -0.209 & -0.148 & -0.164 \\
& Humidity & -0.166 & -0.007 & -0.205 & 0.192 & 0.043 & $0.235^{*}$ & $0.224^{*}$ \\
& Sunshine & -0.043 & $-0.241^{*}$ & $-0.320^{* *}$ & -0.067 & -0.054 & -0.104 & -0.109 \\
\hline \multirow{6}{*}{ Yangshuo } & Air Temp. & -0.184 & -0.100 & $-0.583^{* *}$ & -0.026 & 0.132 & -0.079 & 0.043 \\
& Precipitation & $-0.372^{* *}$ & -0.008 & $-0.359^{* *}$ & 0.195 & $0.261^{*}$ & $0.483^{* *}$ & $0.374^{* *}$ \\
& Streamflow & $-0.487^{* *}$ & -0.111 & $-0.430^{* *}$ & 0.144 & $0.349^{* *}$ & $0.489^{* *}$ & $0.282^{*}$ \\
& Water Temp. & -0.013 & -0.051 & $-0.585^{* *}$ & -0.066 & 0.058 & -0.124 & -0.034 \\
& Wind Speed & $0.259^{*}$ & -0.214 & $0.450^{* *}$ & -0.009 & -0.163 & -0.143 & $-0.234^{*}$
\end{tabular}




\begin{tabular}{lccccccc} 
Humidity & $-0.480^{* *}$ & 0.060 & $-0.271^{*}$ & 0.178 & $0.248^{*}$ & $0.444^{* *}$ & $0.421^{* *}$ \\
Sunshine & 0.166 & -0.055 & $-0.360^{* *}$ & -0.204 & 0.038 & $-0.288^{* *}$ & $-0.257^{*}$ \\
\hline
\end{tabular}

265 Note: “*”: significant at $p<0.05$, “**”: significant at $p<0.01$.

$266 \mathrm{NH}_{4}-\mathrm{N}$ and TP are mainly affected by precipitation, streamflow, humidity, and sunshine 267 duration, of which only sunshine duration is negatively correlated with $\mathrm{NH}_{4}-\mathrm{N}$ and TP. As 268 mentioned above, increased precipitation and runoff cause more surface pollution into the water 269 body. There are a large number of agricultural lands on both sides of the Lijiang River, the low 270 rate of chemical fertilizer usage results in the loss of large amounts of nitrogen and phosphorus 271 to the water body and also increases the consumption of DO. Nitrogen and phosphorus in the 272 atmosphere will settle more easily with higher air humidity (Anderson et al. 2011), and 273 eventually enter the water body with surface runoff. Yangshuo is located in the lower reaches 274 of Guilin, and there are mainly rural areas between Yangshuo and Guilin. Therefore, Yangshuo's $275 \mathrm{NH}_{4}-\mathrm{N}$ and TP have a higher correlation with precipitation, streamflow, and humidity, $\mathrm{NH}_{4}-\mathrm{N}$ 276 achieved a middle correlation $(0.4<\rho<0.6)$ with these 3 climate indicators. Solar radiation will 277 enhance the photosynthesis of aquatic plants and the growth of chlorophyll a, thereby 278 accelerating the consumption and absorption of nitrogen and phosphorus, and inhibiting the 279 nitrogen and phosphorus content of the water body. However, unlike Yangshuo, Guilin's 280 sunshine duration is not significantly correlated with $\mathrm{NH}_{4}-\mathrm{N}$ and TP. Compared to Yangshuo, 281 Guilin will receive more surface runoff through farmland and woodlands, which indicates that 282 the $\mathrm{NH}_{4}-\mathrm{N}$ and TP in the water body are less affected by sunshine than the absorption process 283 of $\mathrm{NH}_{4}-\mathrm{N}$ and $\mathrm{TP}$ by surface plants.

284 The factors influencing $\mathrm{BOD}_{5}, \mathrm{pH}$, and $\mathrm{ORP}$ are different at the two stations. Both $\mathrm{BOD}_{5}$ 285 and $\mathrm{pH}$ in Yangshuo are affected by precipitation, streamflow, and humidity. $\mathrm{BOD}_{5}$ is positively 286 correlated and $\mathrm{pH}$ is negatively correlated, which shows that the pollutants carried by the 287 surface runoff from Guilin to Yangshuo on both sides of the Lijiang River into the water body 288 contain a certain amount of organic matter and acidic matter. The nature of ORP determines 289 that it has a certain correlation with DO. This converging relationship did not emerge in 290 Yangshuo, indicating that a large number of introduced pollutants makes the impact by a single 291 factor on the ORP weakened. Both stations are identical as the $\mathrm{pH}$ is positively correlated with 292 the wind speed. It is also because wind speed promotes the dissolution of oxygen in the water 
293 body and indirectly leads to a decrease in the acidity of the water body.

\section{$294 \quad 3.4$ Sensitivity coefficients}

295 According to formula (3), the sensitivity coefficients of water environment indicators to 296 different climate conditions are calculated, as shown in Table 3. Although precipitation and 297 streamflow have a significant correlation with various water environment indicators, these 298 indicators are not very sensitive to precipitation and streamflow. On the one hand, there is a 299 difference of orders of magnitude. Sensitivity 1 means that the climate factor changes by 1 , and 300 the water environment factors are correspondingly changed by 1. Precipitation and streamflow 301 are often over 1000 orders of magnitude different from the water environment indicators, 302 resulting in low sensitivity. On the other hand, although changes in water environment factors

303 are related to climate, climate conditions have little impact on this process. Similarly, humidity 304 and wind speed are not much different in magnitude between themselves and the water 305 environmental indicators, and it is easier to obtain higher sensitivity. The Lijiang River Basin 306 is located in a subtropical region, and the annual humidity changes are not significant. Therefore,

307 although the sensitivity of $\mathrm{COD}_{\mathrm{Mn}}$ and $\mathrm{BOD}_{5}$ to humidity is extremely sensitive, these two 308 indicators will not cause a huge change in water quality due to sudden changes in humidity.

309 Table 3 Sensitivity coefficients of different water environment indicators to climate conditions

\begin{tabular}{ccccccccc}
\hline & & $\mathrm{pH}$ & $\mathrm{ORP}$ & $\mathrm{DO}$ & $\mathrm{COD}_{\mathrm{Mn}}$ & $\mathrm{BOD}_{5}$ & $\mathrm{NH}_{4}-\mathrm{N}$ & $\mathrm{TP}$ \\
\hline \multirow{6}{*}{ Guilin } & Precipitation & -0.009 & -0.020 & -0.022 & 0.181 & $0.206^{*}$ & 0.151 & 0.031 \\
& Streamflow & -0.020 & -0.136 & $0.208^{*}$ & 0.051 & $0.219^{*}$ & 0.132 & $0.202^{*}$ \\
& Air Temp. & -0.080 & $-0.439^{*}$ & -0.176 & 0.046 & -0.099 & -0.144 & $0.326^{*}$ \\
& Water Temp. & 0.059 & -0.025 & -0.089 & 0.066 & -0.118 & -0.123 & $-0.415^{*}$ \\
& Wind Speed & 0.140 & $0.321^{*}$ & $0.684^{*}$ & $-0.734^{*}$ & $-0.656^{*}$ & $-0.376^{*}$ & $-0.270^{*}$ \\
& Humidity & $-0.332^{*}$ & $-0.938^{*}$ & $-0.236^{*}$ & $1.288^{* *}$ & $1.118^{* *}$ & $0.392^{*}$ & $0.630^{*}$ \\
& Sunshine & -0.088 & -0.044 & 0.019 & $-0.214^{*}$ & $-0.336^{*}$ & $-0.228^{*}$ & $-0.402^{*}$ \\
\hline \multirow{6}{*}{ Yangshuo } & Water Temp. & $-0.258^{*}$ & $-0.235^{*}$ & $-0.498^{*}$ & $-0.439^{*}$ & 0.076 & $-0.523^{*}$ & -0.178 \\
& Precipitation & -0.022 & -0.112 & -0.142 & $0.327^{*}$ & 0.125 & 0.074 & 0.087 \\
& Streamflow & -0.125 & -0.106 & -0.126 & 0.163 & $0.670^{*}$ & 0.198 & 0.184 \\
& Air Temp. & $-0.305^{*}$ & $-0.408^{*}$ & $-0.249^{*}$ & -0.025 & $0.363^{*}$ & $-0.210^{*}$ & $0.747^{*}$ \\
& Wind Speed & 0.191 & $-0.274^{*}$ & $0.295^{*}$ & 0.133 & $-0.293^{*}$ & $-0.208^{*}$ & $-0.518^{*}$ \\
& Humidity & $-0.362^{*}$ & $0.445^{*}$ & $-0.549^{*}$ & $2.204^{* *}$ & $1.904^{* *}$ & $1.013^{* *}$ & $1.992^{* *}$ \\
& Sunshine & 0.049 & -0.065 & -0.064 & -0.086 & 0.124 & $-0.418^{*}$ & $-0.215^{*}$ \\
\hline
\end{tabular}

310 Note: “*”: $0.2<|S(C l)|<1$, highly sensitive, “**”: $|S(C l)|>1$ : extremely sensitive.

311 The sensitivity of water environment indicators to temperature has significant spatial 
differences. Almost all indicators in Yangshuo have high sensitivity to temperature, while

313 Guilin has very low sensitivity to temperature except for TP and ORP. It is worth noting that

314 the sensitivity of TP to air temperature and water temperature is opposite. This is because rising 315 water temperatures will accelerate phosphorus consumption and deposition, and rising air temperatures will bring more exogenous phosphorus to the river.

Overall, the highest absolute value of the sensitivity of each water environment index to climate conditions are air temperature (pH: -0.193, ORP: -0.424), wind speed (DO: 0.490), and humidity $\left(\mathrm{COD}_{\mathrm{Mn}}: 1.746, \mathrm{BOD}_{5}: 1.511, \mathrm{NH}_{4}-\mathrm{N}: 0.703\right.$, TP: 1.311$)$, respectively.

\subsection{Contribution of climate conditions}

Based on the sensitivity of each water environment indicator to climate conditions, the contribution rates of climate conditions to the change of water environment indicators are calculated using formula (4), as shown in Figure 6. Those with contribution rates in excess of $5 \%$ include streamflow to $\mathrm{BOD}_{5}$ at Yangshuo, sunshine duration to $\mathrm{BOD}_{5}$ at Guilin, water temperature to $\mathrm{COD}_{\mathrm{Mn}}$ at Yangshuo, water temperature to DO at Yangshuo, sunshine duration and water temperature to $\mathrm{NH}_{4}-\mathrm{N}$ at Yangshuo, sunshine duration and water temperature to TP at Guilin, and wind speed to TP at Yangshuo. All of them are negative values except for the last one. It seems that the growth of climate indicators may cause a more obvious decline in some water environment indicators.

Water temperature and sunshine duration have a positive impact on the reducing $\mathrm{NH}_{4}-\mathrm{N}$ and $\mathrm{TP}$, with a contribution rate ranging from $2.42 \%$ to $8.77 \%$. Wind speed is the main contribution of climate conditions to the increase of $\mathrm{NH}_{4}-\mathrm{N}$ and TP in the water body. Relatively, the contribution to Yangshuo is greater than that of Guilin. Humidity's contribution to $\mathrm{NH}_{4}-\mathrm{N}$ and TP is positive in Yangshuo and negative in Guilin, which is caused by the difference in exogenous phosphorus. In addition, air temperature is also a big boost to the growth of TP in the water bodies, with the contribution rates of Guilin and Yangshuo reaching 3.56\% and 1.64\%, respectively.

Except for the wind speed, other climate indicators in Guilin have a negative contribution to $\mathrm{BOD}_{5}$, while Yangshuo only precipitation and streamflow have a negative contribution. It shows that various climate conditions can contribute to the reduction of organic matter in the water body to a certain extent where there are few external sources, but in the case of external 

most important factors to promote biochemical reactions, obviously contributes negatively to

344 the concentration of DO in water bodies, and even reaches $-8.35 \%$ in Yangshuo.

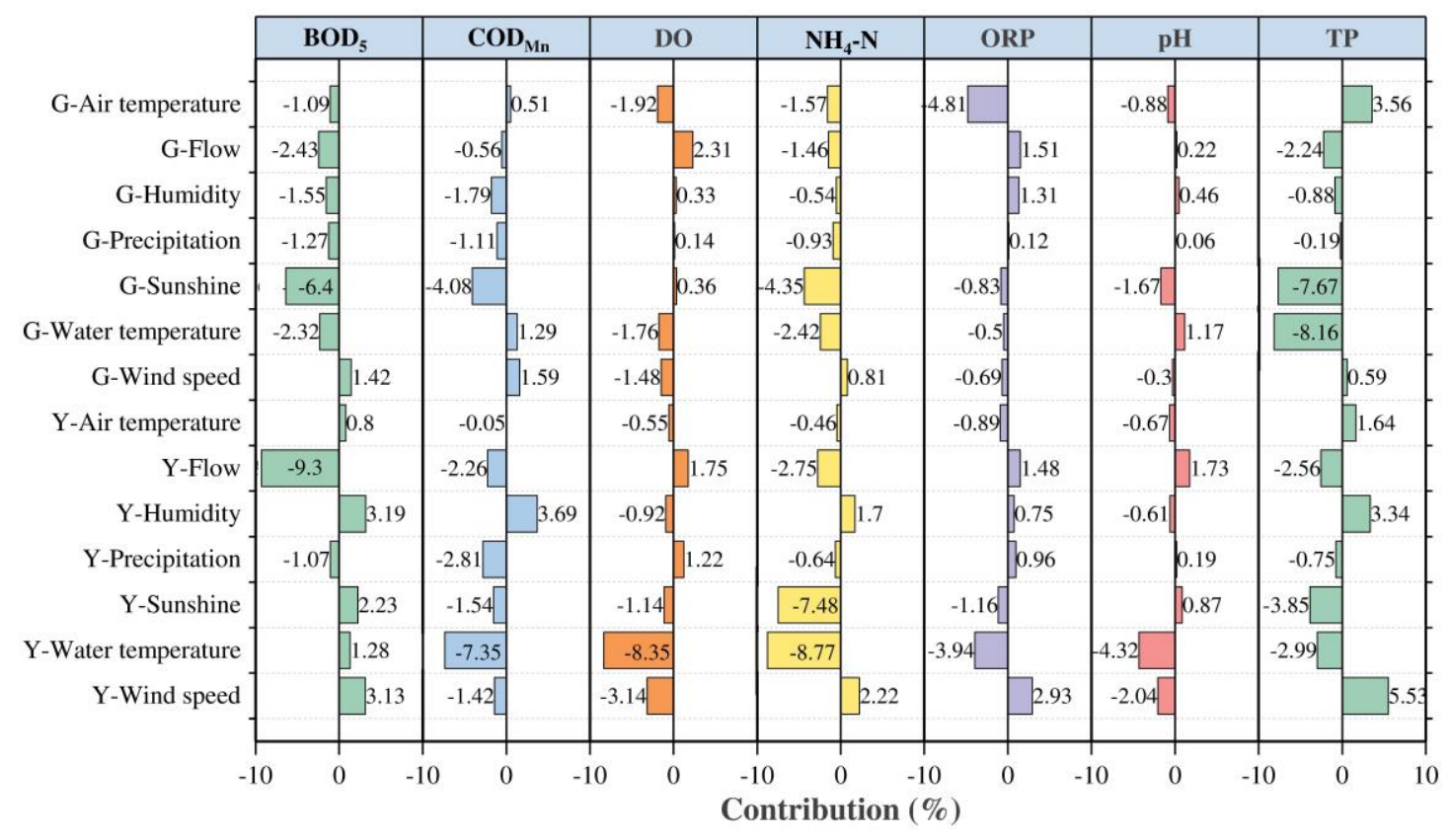

Figure 6 Contribution of climate conditions on water environment indicators

To explore the contribution of climate conditions of individual stations to water environment indicators, the climate conditions with the highest contribution rate of the water environment of each station are defined as the dominant factors of the station. The dominant

350 factors of each station are shown in Table 4. Water temperature is the dominant factor of 5 indicators in Yangshuo, and sunshine duration is the dominant factor of 4 indicators in Guilin.

352 No climate condition can dominate one water environmental indicator of two stations at the same time. An enormous difference between the 2 stations shows that the impact of climate

354 conditions on the water environment has large spatial differences. At the same time, compared 355 with other external conditions, the impact of climate conditions on the changes of the water 356 environment is very limited.

Table 4 Dominant factor of different monitoring stations

\begin{tabular}{ccc}
\hline Environment factors & Guilin & Yangshuo \\
\hline $\mathrm{pH}$ & Sunshine duration & Water Temperature \\
$\mathrm{ORP}$ & Air Temperature & Water Temperature \\
$\mathrm{DO}$ & Streamflow & Water Temperature \\
$\mathrm{COD}_{\mathrm{Mn}}$ & Sunshine duration & Water Temperature \\
$\mathrm{BOD}_{5}$ & Sunshine duration & Streamflow
\end{tabular}


$\mathrm{NH}_{4}-\mathrm{N}$

$\mathrm{TP}$
Sunshine duration

Water Temperature
Water Temperature

Wind Speed

\section{6 discussion and management}

The difference in the contribution rate of the climate conditions between Yangshuo and

361 Guilin to the water environment is shown in Table 5. Under normal circumstances, lower

$362 \mathrm{COD}_{\mathrm{Mn}}, \mathrm{BOD}_{5}, \mathrm{NH}_{4}-\mathrm{N}$, and $\mathrm{TP}$, higher DO always means better water quality. Comparing with

363 the change trend of climate conditions (Figure 2), indicators with a risk of deterioration are

364 marked with "**" (Table 5). These differences are mainly due to the different pollution in the

365 two places, therefore the impact of the climate conditions is different.

366

Table 5 Difference of contribution rate between Yangshuo and Guilin (\%)

\begin{tabular}{cccccccc}
\hline & $\mathrm{pH}$ & $\mathrm{ORP}$ & $\mathrm{DO}$ & $\mathrm{COD}_{\mathrm{Mn}}$ & $\mathrm{BOD}_{5}$ & $\mathrm{NH}_{4}-\mathrm{N}$ & $\mathrm{TP}$ \\
\hline Precipitation & 0.13 & 0.84 & $1.08^{*}$ & $-1.70^{*}$ & 0.20 & 0.29 & $-0.56^{*}$ \\
Streamflow & 1.51 & -0.03 & -0.56 & $-1.70^{*}$ & $-6.87^{*}$ & $-1.29^{*}$ & $-0.32^{*}$ \\
Air Temperature & 0.21 & 3.92 & 1.37 & -0.56 & $1.89^{*}$ & $1.11^{*}$ & -1.92 \\
Water Temperature & -5.49 & -3.44 & $-6.59^{*}$ & -8.64 & $3.60^{*}$ & -6.35 & $5.17^{*}$ \\
Wind Speed & -1.74 & 3.62 & -1.66 & $-3.01^{*}$ & 1.71 & 1.41 & 4.94 \\
Humidity & -1.07 & -0.56 & $-1.25^{*}$ & $5.48^{*}$ & $4.74^{*}$ & $2.24^{*}$ & $4.22^{*}$ \\
Sunshine duration & 2.54 & -0.33 & $-1.50^{*}$ & $2.54^{*}$ & $8.63^{*}$ & -3.13 & $3.82^{*}$ \\
\hline
\end{tabular}

Note: "*" means water quality has the risk of deterioration.

Through data analysis, it can be seen that the difference between Yangshuo and Guilin is mainly due to the input of external sources on both sides of the Lijiang River, which leads to the difference in sensitive climate conditions. Sunshine duration, humidity, and precipitation all

371 indirectly affect the water quality of the Lijiang River by affecting the pollutants on the shore.

372 Therefore, the construction of non-point source pollution reduction facilities such as

373 constructed wetlands on both banks of the Lijiang River can effectively cope with the

374 deterioration of water quality in the lower reaches of the Lijiang River caused by climate change.

375 As a world-famous tourist city, Guilin has many foreign tourists all year round, the Lijiang

376 River from Guilin to Yangshuo is the most frequent tourist route, thus this section has suffered

377 the great risk of deteriorating the quality of the water environment by the sewage discharge.

378 The construction of sewage treatment measures along the river is also very necessary. 


\section{Conclusion}

Based on the meteorological, hydrological, and water quality data of two stations in the middle and lower reaches of the Lijiang River from 2012 to 2018, this paper elaborates on the temporal and spatial distribution of climate conditions and water environment indicators, analyzes the correlation between climate conditions and water environment indicators. Attribute the water environment indicators to the climate conditions through sensitivity analysis and contribution assessment. Based on the difference between the analytical results of Guilin and Yangshuo, propose a water environmental protection and restoration plan to deal with climate change. The main conclusions are as follows:

(1) Air temperature, water temperature, and sunshine duration increase year by year, the temperature in Guilin gradually exceeds that of Yangshuo due to the heat island effect; precipitation and streamflow decrease over time, precipitation in Guilin has a greater impact on the downstream than in local areas; wind speed at both stations and the humidity in Guilin decreased, and the humidity in Yangshuo increased. The oxidation and alkalinity of the water in the Lijiang River Basin gradually increase, and the intensity becomes stronger as it goes downstream. DO increase and the concentrations of $\mathrm{COD}_{\mathrm{Mn}}, \mathrm{BOD}_{5}$, and $\mathrm{NH}_{4}-\mathrm{N}$ all decreased, and water quality improved year by year. The input of external pollution has led to an upward trend in TP at Yangshuo.

(2) Except for the positive correlation between wind speed and DO, other climate indicators are negatively correlated with DO. $\mathrm{NH}_{4}-\mathrm{N}$ and $\mathrm{TP}$ are mainly affected by precipitation, streamflow, humidity, and sunshine duration; only sunshine duration is negatively correlated with $\mathrm{NH}_{4}-\mathrm{N}$ and TP. Pollutants from Guilin to Yangshuo on both sides of the Lijiang River were carried by the surface runoff into the water body contain a certain amount of organic matter and acidic matter. Water environment indicators are not very sensitive to precipitation and streamflow, humidity and wind speed have higher sensitivity; the sensitivity of $\mathrm{COD}_{\mathrm{Mn}}$ and $\mathrm{BOD}_{5}$ to humidity is extremely sensitive, these two indicators will not cause huge water quality changes due to sudden changes in humidity. Almost all indicators in Yangshuo have high sensitivity to temperature, while Guilin has very low sensitivity to temperature except for TP and ORP. 
(3) Water temperature and sunshine duration have a positive impact on the reducing $\mathrm{NH}_{4}$ -

$409 \mathrm{~N}$ and $\mathrm{TP}$, with a contribution rate ranging from $2.42 \%$ to $8.77 \%$. Contribution rates of air 410 temperature at Guilin and Yangshuo are 3.56\% and 1.64\%, respectively. Various climate 411 conditions can help reduce organic matter in the water body when there are few external sources, 412 but in the case of external sources, these climate conditions will make the reverse contribution.

413 No climate condition can dominate one water environment indicator of two stations at the same 414 time, the impact of climate conditions on the water environment have great spatial differences.

415 The difference between Yangshuo and Guilin is mostly due to the input of external sources on 416 both sides of the Lijiang River, which leads to the difference in sensitive climate conditions.

417 Construction of non-point source pollution reduction facilities and sewage treatment measures 418 are very necessary.

\section{Declarations}

420 Ethics approval and consent to participate Not applicable

421 Consent for publication Not applicable

422 Data availability All data generated or analyzed during this study are included in this published 423 article.

424 Competing interests The authors declare that they have no competing interests.

425 Funding This study is funded by Project funded by Guangxi Key R\&D Program 426 (AB18221108), China Postdoctoral Science Foundation (2020M672635), Guangdong Basic 427 and Applied Basic Research Foundation (2020A1515111152), and Guangdong Provincial Key 428 Laboratory of Modern Civil Engineering Technology (2021B1212040003). All the sources of 429 support are gratefully acknowledged.

430 Authors' contributions Dantong Zhu: Investigation, analysis, visualization, writing; Xiangju 431 Cheng: Conceptualization, methodology, review, editing, supervision, funding acquisition, 432 paper administration; Wuhua Li: Methodology, investigation; Fujun Niu: Review, editing; 433 Jianhui Wen: Investigation, review.

\section{Reference}

435 Ahmadalipour A, Moradkhani H, Castelletti A, Magliocca N (2019) Future drought risk in 436 Africa: Integrating vulnerability, climate change, and population growth. Sci Total 
Anderson CR, Condron LM, Clough TJ, et al (2011) Biochar induced soil microbial community change: Implications for biogeochemical cycling of carbon, nitrogen and phosphorus. Pedobiologia (Jena) 54:309-320. https://doi.org/10.1016/J.PEDOBI.2011.07.005

Bai X, Shen W, Wang P, et al (2020) Response of Non-point Source Pollution Loads to Land Use Change under Different Precipitation Scenarios from a Future Perspective. Water Resour Manag 20203413 34:3987-4002. https://doi.org/10.1007/S11269-020-02626-0

Dai A, Zhao T, Chen J (2018) Climate Change and Drought: a Precipitation and Evaporation Perspective. Curr Clim Chang Reports 201843 4:301-312. https://doi.org/10.1007/S40641-018-0101-6

Grafton RQ, Pittock J, Davis R, et al (2012) Global insights into water resources, climate change and governance. Nat Clim Chang 2012 34 3:315-321. https://doi.org/10.1038/nclimate1746

Hosseini N, Johnston J, Lindenschmidt K-E (2017) Impacts of Climate Change on the Water Quality of a Regulated Prairie River. Water 2017, Vol 9, Page 199 9:199. https://doi.org/10.3390/W9030199

Li N, Wang J, Wang H, et al (2021) Impacts of land use change on ecosystem service value in Lijiang River Basin, China. Environ Sci Pollut Res 2021 1-16. https://doi.org/10.1007/S11356-020-12190-0

Li R, Chen Q, Tonina D, Cai D (2015) Effects of upstream reservoir regulation on the hydrological regime and fish habitats of the Lijiang River, China. Ecol Eng 76:75-83. https://doi.org/10.1016/J.ECOLENG.2014.04.021

Li T, Kim G (2019) Impacts of Climate Change Scenarios on Non-Point Source Pollution in the Saemangeum Watershed, South Korea. Water 2019, Vol 11, Page 1982 11:1982. https://doi.org/10.3390/W11101982

Liu G, Jin Q, Li J, et al (2017) Policy factors impact analysis based on remote sensing data and the CLUE-S model in the Lijiang River Basin, China. CATENA 158:286-297. https://doi.org/10.1016/J.CATENA.2017.07.003

Luo W, Yang S, Khan MA, et al (2020) Mitigation of Cd accumulation in rice with water 
management and calcium-magnesium phosphate fertilizer in field environment. Environ Geochemistry Heal 20204211 42:3877-3886. https://doi.org/10.1007/S10653-02000648-6

McCuen RH (1974) A SENSITIVITY AND ERROR ANALYSIS CF PROCEDURES USED FOR ESTIMATING EVAPORATION1. JAWRA J Am Water Resour Assoc 10:486497. https://doi.org/10.1111/J.1752-1688.1974.TB00590.X

Olaoye IA, Confesor RB, Ortiz JD (2021) Effect of Projected Land Use and Climate Change on Water Quality of Old Woman Creek Watershed, Ohio. Hydrol 2021, Vol 8, Page 62 8:62. https://doi.org/10.3390/HYDROLOGY8020062

Peng L, Liu JP, Wang Y, et al (2018) Wind weakening in a dense high-rise city due to over nearly five decades of urbanization. Build Environ 138:207-220. https://doi.org/10.1016/J.BUILDENV.2018.04.037

Qiu J, Shen Z, Chen L, Hou X (2019) Quantifying effects of conservation practices on nonpoint source pollution in the Miyun Reservoir Watershed, China. Environ Monit Assess 20191919 191:1-21. https://doi.org/10.1007/S10661-019-7747-Y

Schober P, Schwarte LA (2018) Correlation coefficients: Appropriate use and interpretation. Anesth Analg 126:1763-1768. https://doi.org/10.1213/ANE.0000000000002864

Shrestha S, Bhatta B, Shrestha M, Shrestha PK (2018) Integrated assessment of the climate and landuse change impact on hydrology and water quality in the Songkhram River Basin, Thailand. Sci Total Environ 643:1610-1622. https://doi.org/10.1016/J.SCITOTENV.2018.06.306

Sjerps RMA, ter Laak TL, Zwolsman GJJG (2017) Projected impact of climate change and chemical emissions on the water quality of the European rivers Rhine and Meuse: A drinking water perspective. Sci Total Environ 601-602:1682-1694. https://doi.org/10.1016/J.SCITOTENV.2017.05.250

Sowers J, Vengosh A, Weinthal E (2010) Climate change, water resources, and the politics of adaptation in the Middle East and North Africa. Clim Chang 20101043 104:599-627. https://doi.org/10.1007/S10584-010-9835-4

Stackpoole SM, Stets EG, Sprague LA (2019) Variable impacts of contemporary versus legacy agricultural phosphorus on US river water quality. Proc Natl Acad Sci U S A 
Wang H, Yan W, Wang J, Duan W (2020) Exploring Distribution Rules and Variation Trends of Precipitation in the Upper Lijiang River from 1951 to 2016, Guangxi Province, China. J Coast Res 105:1-5. https://doi.org/10.2112/JCR-SI105-001.1

Wang X, Li Z, Li M (2018a) Impacts of climate change on stream flow and water quality in a drinking water source area, Northern China. Environ Earth Sci 2018 7711 77:1-14. https://doi.org/10.1007/S12665-018-7581-5

Wang Y, Yang J, Liang J, et al (2018b) Analysis of the environmental behavior of farmers for non-point source pollution control and management in a water source protection area in China. Sci Total Environ 633:1126-1135. https://doi.org/10.1016/j.scitotenv.2018.03.273

Xiao H, Shahab A, Xi B, et al (2021) Heavy metal pollution, ecological risk, spatial distribution, and source identification in sediments of the Lijiang River, China. Environ Pollut 269:116189. https://doi.org/10.1016/J.ENVPOL.2020.116189

Yu CQ, Huang X, Chen H, et al (2019) Managing nitrogen to restore water quality in China. Nature 567:516-520. https://doi.org/10.1038/s41586-019-1001-1

Zhao H, Xiao Q, Miao Y, et al (2020) Sources and transformations of nitrate constrained by nitrate isotopes and Bayesian model in karst surface water, Guilin, Southwest China. Environ Sci Pollut Res 20202717 27:21299-21310. https://doi.org/10.1007/S11356- 